\title{
Beyond Oxidized LDL: The Initiation and Progression of Atherosclerosis
}

\author{
Nobuyoshi Hirose, Yasumichi Arai, Masahide Kawamura and Hiroshi Shigematu \\ Department of Geriatric Medicine, School of Medicine, Keio University, Tokyo, Japan \\ (Received for publication on November 30, 1995)
}

\begin{abstract}
Oxidized-low density lipoprotein (ox-LDL) exhibits various atherogenic properties, such as the formation of foam cells, the recruitment of macrophages into arteries, the promotion of cell growth, the formation of thrombi, and the development of vasoconstriction. Antioxidants inhibit atherosclerosis in cholesterol-fed animals by preventing the recruitment of macrophages into the arteries suggesting that oxidation is important for such recruitment of macrophages, and that it is responsible for early development of atherosclerosis. Calcification and an increase in extracellular matrix (ECM) are frequently observed in advanced atherosclerosis. These processes are active and regulated, not passive and degenerative, and do not appear to be controlled by ox-LDL. The control of calcifications and ECM increase will provide new directions in the treatment of atherosclerosis especially in the advanced stages. Future treatment should include strategies to inhibit the calcification and the increase in ECM. (Keio J Med 45 (2): 90-94, June 1996)
\end{abstract}

Key words: oxidized LDL, atherosclerosis, calcification, extracellular matrix

\section{Introduction}

High circulating levels of cholesterol, and low density lipoprotein (LDL), a major cholesterol carrier in plasma, are principal risk factors in atherosclerosis which is a major cause of death in western countries. Epidemiologic studies have shown that an elevated LDL cholesterol level is associated with a high incidence of coronary heart disease. ${ }^{1}$ Subendothelial accumulation of foam cells, which are derived from macrophages and smooth muscle cells, is a characteristic of atherosclerosis. Although LDL itself does not generate foam cells in vitro, oxidized LDL has various atherogenic properties and is considered to play a key role in atherosclerosis, especially in the early phase. ${ }^{2}$

This review examines the ox-LDL on atherosclerosis and the effects of antioxidant treatment in animals and humans. Pathological changes observed in advanced atherosclerosis, such as calcification and an increase in the extracellular matrix, which are not caused by oxLDL are also discussed.
The LDL Paradox

Lipids such as cholesterol and triglycerides are insoluble in water. In plasma, they form a complex with protein and circulate as lipoproteins. About two-thirds of the cholesterol is transported in LDL, about one quarter of cholesterol is in high density lipoprotein(HDL) and the rest is in very low density lipoprotein(VLDL). Epidemiologic studies have shown that an elevated level of cholesterol, especially LDL cholesterol, is associated with a high incidence of coronary heart disease and the role of LDL in atherosclerosis has been investigated. The accumulation in the intima of foam cells, which are derived from macrophages and smooth muscle cells by uptake of LDL, are a characteristic of atherosclerosis. Foam cells contain a large amount of lipid droplets that consist of cholesterol ester. Studies have failed to generate foam cells even when large quantity of LDL was added to macrophages in culture. The discrepancy between epidemiologic findings and the results of experimental studies has been described as the "LDL paradox" by Steinberg. ${ }^{3}$ In 1979, Goldstein and Brown showed that chemically

広瀬信義, 新井康通, 川村昌嗣, 重松 洋

Reprint requests to: Dr Nobuyoshi Hirose, Department of Geriatric Medicinc, School of Medicine, Keio University, 35 Shinanomachi, Shinjukuku, Tokyo 160, Japan 
acetylated LDL generated foam cells from macrophages in culture. ${ }^{4}$ Acetylated LDL was taken up via a specific, saturable receptor which has been cloned and called a scavenger receptor. ${ }^{5}$ Other types of modified LDL, such as malondialdehyde-conjugated LDL these are also taken up by the scavenger receptors. However types of modified LDL do not occur in vivo. In 1981, Henriksen et al reported that the LDL incubated with endothelial cells in the absence of serum was modified and taken up by macrophages via scavenger receptors. ${ }^{6}$ Other cells, such as monocyte/macrophages and smooth muscle cells, also modify LDL in a similar manner. This modification has been found to result from oxidation. ${ }^{7}$ Because the oxidation of LDL likely occurs in vivo, the properties of oxLDL and the means by which it is generated are of clinical interest.

\section{Characteristics of Ox-LDL}

The oxidation of LDL occurs in three phases. ${ }^{2}$ In the initiation phase, antioxidants in LDL (Vitamin E, betacarotene) are depleted and LDL-contains a limited number of lipoperoxides. It is difficult to detect ox-LDL in the initiation phase. In the propagation phase, hydroperoxides are generated rapidly and a rearrangement of double bond in fatty acids occurs. In this phase, absorbance of $234 \mathrm{~nm}$ and chemiluminescence are increased, and there is an increase in the peroxide levels as determined by iodometric measurement of TBARS. In the decomposition phase, reactive aldehydes are generated from polyunsaturated fatty acid fragmentations. Aldehydes react with LDL components, such as apolipoprotein B-100. As the modification of apoB progresses, LDL becomes negatively charged, its affinity for LDL receptors decreases and its affinity for scavenger receptors or oxidized receptors increases. Some investigators use minimally modified LDL (MM-LDL) to represent partially modified LDL that is recognized by LDL recep-

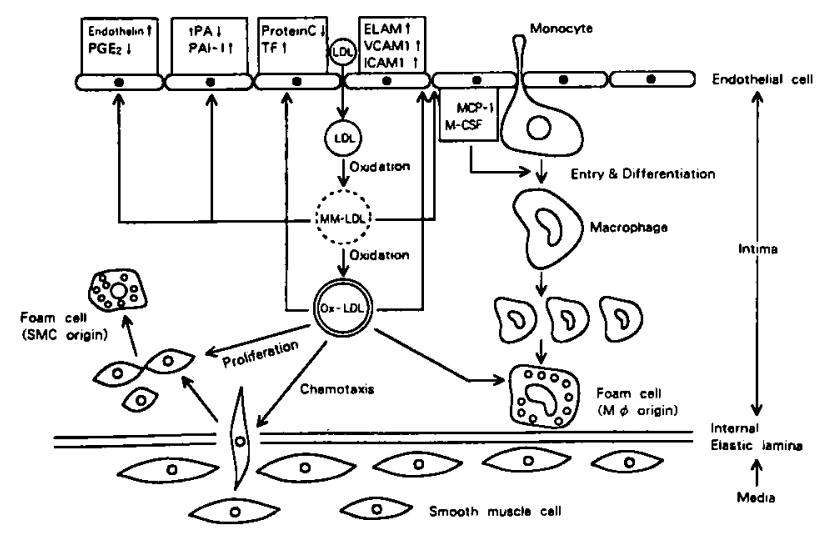

tors but not by scavenger receptors. ${ }^{8}$ LDL can be oxidized by incubation with cells such as endothelial cells, macrophages and smooth muscle cells, or with redox-active metals (copper or iron). Oxidation of LDL does not occur in the circulation because of the presence of antioxidants in plasma, this suggests that oxidation may perhaps occur in the arterial wall.

\section{Presence of Ox-LDL in Atherosclerotic Lesions}

Before ox-LDL was recognized, LDL extracted from atherosclerotic lesions was found to be negatively charged and to be capable of generating foam cells in vitro. 9,10 These characteristics are consistent with the features of ox-LDL. Studies using antibodies against ox-LDL have confirmed the presence of ox-LDL in atherosclerotic lesions. ${ }^{11,12}$ LDL extracted from arterial lesions is also recognized by these antibodies. Presence of ox-LDL in plasma has been investigated, several laboratories reported the presence of ox-LDL in human plasma. However it is accepted ox-LDL is present in arterial wall and is usually generated in the arterial wall.

\section{Properties of Ox-LDL}

Ox-LDL exhibits various atherogenic functions (Fig 1). ${ }^{13}$ Foam cell formation is mediated by the uptake of ox-LDL via scavenger receptors and ox-LDL receptors. Ox-LDL also induces the expression of scavenger receptors in smooth muscle cells and accelerates the formation of foam cells.

Ox-LDL is cytotoxic to macrophages, endothelial cells, smooth muscle cells and other types of cells. Ox-LDL injures or kills cells in the arterial walls. And some investigators have suggested that ox-LDL induces apoptosis.

Ox-LDL attracts monocytes from the circulation and inhibits the motility of tissue macrophages. This function

Fig 1 The effects of Ox-LDL on atherosclerosis. Ox-LDL stimulates the secretion of adhesion molecules by endothelial cells and the secretion of MCP-1, and M-CSF, causing monocytes to enter the artery and to become differentiated into macrophages. Ox-LDL are taken up by scavenger receptors of macrophages, resulting in foam cell formation. Ox-LDL, especially MM-LDL, stimulate the secretion of tissue factor and suppresses protein C. t-PA and PAI-1, resulting in hypercoagulation and hypofibrinolysis. Ox-LDL stimulates the synthesis of endothelin and inhibits PGE2 by endothelial cells, resulting in impaired vasodilation. Ox-LDL stimulates migration of smooth muscle cells into the intima and induccs cell proliferation. Ox-LDL is also taken up by scavenger receptors expressed by smooth muscle cells, resulting in foam cell formation. LDL; low density lipoprotein, Ox-LDL; oxidized LDL, MCP-1; monocyte chemoattractant protein-1, MM-LDL; minimally modified LDL, t-PA; tissue plasminogen activator, M-CSF; macrophage colony-stimulating factor, PAI-1; plasminogen activator inhibitor-1, PGE2; prostaglandin E2. 
is due to the stimulated synthesis of adhesion molecules (ELAM-1, ICAM-1, VCAM-1) and the production of chemoattractant factors (MCP-1) in endothelial cells. It also induces the migration and proliferation of smooth muscle cells in the intima by stimulating the production of growth factors. (PDGF, bFGF) and the synthesis of receptors.

Ox-LDL is prothrombotic. It induces an increase in the expression of tissue factor and inhibits the production of protein $\mathrm{C}$ by endothelial cells, resulting in thrombin formation. Thrombin in turn induces platelet aggregation. Ox-LDL also induces hypofibrinolysis by increasing the levels of plasminogen activator inhibitor-1 (PAI-1) and inhibiting the synthesis of tissue-type plasminogen activator (t-PA). Finally, ox-LDL impairs the vasodilatory capacity of arteries by inhibiting $\mathrm{NO}$ and $\mathrm{PGE}_{2}$ synthesis and stimulating endothelin synthesis.

\section{Effects of Antioxidant on Atherosclerosis}

Vitamin $E$ is a natural antioxidant that has been shown to inhibit oxidation of $\mathrm{LDL}$ in vitro. Epidemiologic studies $^{14,15}$ show that high doses of vitamin E (500 to $1000 \mathrm{U} /$ day) significantly reduced the incidence of coronary heart disease in 40,000 men and 80,000 women. However, these reports did not provide the subjects cholesterol levels. Probucol, a synthetic compound, that was originally developed as a lipid-lowering agent, has potent antioxidant properties, reduces cholesterol levels, and stimulates cholesterol ester transfer activity, resulting in decreases in the plama levels of cholesterol and HDL cholesterol. ${ }^{16}$ Probucol significantly reduced the rate of development of atherosclerotic lesions in LDL receptordeficient Watanabe heritable hyperlipidemic (WHHL) rabbits, compared with rabbits treated with lovastatin, an HMG-CoA reductase inhibitor that lowers cholesterol, even though the plasma levels of cholesterol were comparable in both groups. ${ }^{17}$ Kita et al also found similar results. ${ }^{18}$ O'Brien et al reported that atherosclerotic lesions in probucol-treated WHHL rabbits were significantly smaller and contained smaller amounts of cellular components than lesions in control rabbits. Smooth muscle cells predominated in the lesions in probucol-treated rabbits, whereas macrophages predominated in lesions in control rabbits. ${ }^{19}$ The above-cited studies indicate that probucol treatment inhibits the progress of atherosclerosis and reduces the content of macrophage in lesions in rabbit.

Sasahara et al found that probucol caused a significant reduction in the area of lesions in the thoracic aortas of Macaca nemestrina fed a high-fat, high-cholesterol diet, compared with the untreated animals. Plasma cholesterol levels in both groups were adjusted by diet, since probucol lowers plasma cholesterol level. And probucol had no significant effect on lesions in the abdominal aortas or iliac arteries. ${ }^{20}$ Histological examination of lesions showed that in the probucol-treated group, lesions are less mature had a thin fibrous overlayer, and had decreased amounts of connective tissue and calcification than untreated animals. Foam cells derived from macrophage were reduced, but smooth muscle cell-derived foam cells were abundant. Medial smooth muscle cells contained lipid, which is not observed in control animals. These findings are consistent with the findings of O'Brien et al. Investigators involved in the pathological determinants of atherosclerosis in Youth (PDAY) Group have reported that in young individuals, macrophages and lymphocytes are more prevalent in the thoracic aorta, where lesions progress slowly, than in the abdominal aorta, where lesions are more advanced. They also reported that areas positive for apoB, a major apolipoprotein of $\mathrm{LDL}$, was similar in thoracic and abdominal aortas, suggesting that infiltration of LDL is nearly same throughout aorta. ${ }^{21}$

PDAY's results may explain why atherosclerotic lesions in the thoracic aorta are inhibited by probucol. Probucol may essentially inhibit monocyte/macrophage recruitment int aorta, ${ }^{22}$ resulting in inhibition of atherosclerosis in the thoracic aorta, where macrophages predominate, but not in the abdominal aorta, where smooth muscle cells predominate.

In the Probucol Quantitative Regression Swedish Trial (PQRST), 274 hypercholesterolemic subjects were treated with diet and cholestyramine, which is a cholesterollowering agent but not an antioxidant for 3 months. Then half of the patients received probucol and half placebo in addition to cholestyramine. Patients were followed up for 3 years. Angiography of the femoral artery was performed annually and the lumen volume was calculated. After 3 years, LDL-cholesterol level was $12 \%$ lower and HDL cholesterol level was $24 \%$ lower in probucol-treated subjects than in placebo-treated subjects. In the probucol-treated group, the lumen volume increased by only $0.6 \%$ compared with a $4.2 \%$ increase in placebo-treted group. Lumen volume of placebotreated group was significantly higher than probucoltreated group after 3 year treatment. ${ }^{23}$ The PQRST also showed that probucol did not improve atherosclerosis in the femoral arteries.

Probucol is a potent antioxidant that also reduces the level of HDL, which is an antiatherogenic lipoprotein. HDL does not inhibit monocyte/macrophage recruitment. Therefore probucol appears to inhibit the recruitment of monocyte/macrophages into arteries by its antioxidant effects. Oxidation of LDL results principally in acceleration of recruitment of macrophages in vivo, although it also has other effects.

\section{Beyond Ox-LDL}

Although data show that ox-LDL is atherogenic and 
plays a major role in atherosclerosis, especially in the early phase, the effects of antioxidants on atherosclerosis are limited, as described above. Theoretically, antioxidants should prevent atherosclerosis, if they are used before atherosclerosis develops. However antioxidant use in children is not practical, because the long-term safety has not been established.

A numbers of the process involved in atherosclerosis may not be induced by ox-LDL, such as calcification and increase in extracellular matrix (ECM) frequently observed in the advanced stage of atherosclerosis.

Analysis of calcified atherosclerotic lesions has shown that substances present in the bone were found in the arterial wall. ${ }^{24}$ Calcium deposits in atherosclerotic lesions appear to be of osteogenic origin. Hydroxyapatite, which is a calcium phosphate found in bone and bone morphogenetic protein 2a (BMP 2), a potent osteogenic differentiation factor, have been identified in calcified atherosclerotic lesions. Osteolcalcin which is synthesized by the osteoblasts is present in lesions of advanced atherosclerosis, and osteopontin whic is important for hydroxyapatite formation, is expressed in human atherosclerotic lesions. Osteonectin, which is closely associated with hydroxyapatite and collagen, has been detected in the arterial wall. Proteoglycans, collagen subtypes present in bone, are also synthesized by vascular smooth muscle cells, and are present in atherosclerotic lesions.

Boström et al has cloned cells from the aortic media that produce hydroxyapatite in vitro. These cells resemble the pericytes and are present in the aortic intima, and less often in the media. The presence in arteries of hydroxyapatite-producing cells and substances normally found in bone suggests that the mechanism of calcification in the arterial wall is similar to that of bone calcification. Ox-LDL does not induce osteocalcin mRNA in macrophages, ${ }^{25}$ indicating that calcification in atherosclerosis is not a passive, degenerative change, but an active, regulated process, which suggests that calcification can be controlled.

An increase in ECM is also a characteristic of atherosclerosis and may not be induced by ox-LDL. Increased levels of collagens, elastin, proteoglycans, fibronectin, laminin, vitronectin and other glycoproteins have been observed in atherosclerotic lesions. ${ }^{26}$ These molecules were once considered to be inert and only fill the space. But now they are shown to possess various properties that contribute to atherosclerosis. Collagens and elastin can bind LDL and ox-LDL and contribute to modification of LDL. Fragmented elastin is a chemoattractant for macrophages. Proteoglycans are composed of core protein and long disaccharide repeats (GAG) and can bind lipoproteins, lipoprotein lipase, coagulation factors and various cytokines, such as TGF- $\beta$, heparin-binding EGF, bFGF. Fibronectin, laminin, and vitronectin can attach cells and support cell motility and cell growth. ECM also bind LDL, contributing the deposit of lipids in the arterial wall. Thus, these molecules constitute the ECM and also mediate the communication between cells and extracellular environments. Many molecules are synthesized by cells in the arterial wall, such as endothelial cells, smooth muscle calls and fibroblasts, and a numbers of factors regulate synthesis of ECM. TGF- $\beta$ is considered to be principally responsible for the increase of ECM through direct upregulation of factors involved in connective tissue synthesis, such as collagen, elastin, proteoglycan and other matrix proteins, and through the inhibition of matrix-degrading enzymes, such as matrix metalloproteinases. Ox-LDL does not appear to influence the induction of TGF- $\beta$ induction by arterial wall cells.

Although many of the functions of ECM have been identified, its role in atherosclerosis is not clear. It remains to be determined whether ECM has a protective role or not. Strategies directed towards controlling increase in ECM and calcification in arteries may provide new treatment options for atherosclerosis, especially in the advanced stages.

Future directions in the treatment of atherosclerosis should include the control of risk factors, such as hypercholesterolemia, hypertension and smoking, the use of natural antioxidants, such as vitamins $E$ and $C$ and $\beta$-carotene, and the control of calcification and the increase in ECM.

Acknowledgements: The authors are grateful to Professor Yoshiro Nakamura, Keio University, and Professor Yoshiya Hata, Kyorin University for their helpful suggestions during the preparation of this manuscript.

\section{References}

1. Kane JP, Havel RT: Disorders of the biogenesis and secretion of lipoproteins containing the B Apolipoproteins. In: Scriver CR, Beaudet AL, Sly WS, Valle D, eds, The Metabolic and Molecular Basis of Inherited Disease 7th Ed, New York, McGraw-Hill, 1995, 1853-1886

2. Witztum JL, Steinberg D: Role of oxidized low density lipoprotein in athcrogenesis. J Clin Invest 1991, 88: 1785-1792

3. Steinberg D, Parthasarthy S, Carew TE, Khoo JC, Witztum JL: Beyond cholesterol: modification of low-density lipoprotein that increase its atherogenicity. N Engl J Med 1981, 320: 915-924

4. Goldstein JL, Ho YK, Basu SK, Brown MS: Binding site on macrophages that mediates uptake and dcgradation of acetylated low density lipoprotein, producing massive cholesterol deposition. Proc Natl Acad Sci USA 1979, 76: 333-337

5. Kodama T. Freeman M, Rohrer L, Zabrecky J, Matsudaira P, Krieger $M$ : Type 1 macrophage scavenger receptor contains alpha-helical and collagen-like coiled coils. Nature 1990, 343: $531-535$

6. Henriksen T, Mahoney EM, Steinberg D: Enhanced macrophage degradation of low density lipoprotein previously incubated with cultured endothelial cells: recognition by receptors for acetylated low density lipoproteins. Proc Natl Acad Sci USA 1981, 78: 6499-6503

7. Steinbrecher UP, Parthasarathy S. Leake DS, Witztum JL, 
Steinberg D: Modification of low density lipoprotein by endothelial cells involves lipid peroxidation and degradation of low density lipoprotein phospholipids. Proc Natl Acad Sci USA 1984, 81: $3883-3887$

8. Berliner JA, Territo MC, Sevanian A, Ramin S, Kim JA, Bamshad B, Esterson M, Fogelman AM: Minimally modified low density lipoprotein stimulates monocyte endothelial interactions. J Clin Invest 1990, 85: 1260-1266

9. Hoff HF, Gaubat JW: Isolation, purification, and characterization of a lipoprotein containing Apo B from the human aorta. Atherosclerosis 1982, 42: 273-297

10. Haberland ME, Fong D, Cheng L: Malondialdehyde-altered protein occurs in atheroma of Watanabe heritable hyperlipidemic rabbits. Science 1988, 241: 215-218

11. Ylä-Herttuala S, Palinski W, Rosenfeld ME, Parthasarathy S, Carew TE, Butler S, Witztum JL, Steinberg D: Evidence for the presence of oxidatively modified low density lipoprotein in atherosclerotic lesions of rabbit and man. J Clin Invest 1989, 84: 10861095

12. Palinski W, Ylä-Herttuala S, Rosenfeld ME. Butler SW, Socher SA, Parthasarathy S, Curtiss LK, Witztum JL: Antisera and monoclonal antibodies specific for epitopes generated during oxidative modification of low density lipoprotein. Arteriosclerosis 1990, 10: $325-335$

13. Holvoet $\mathbf{P}$, Collen $\mathbf{D}$ : Oxidized lipoproteins in atherosclerosis and thrombosis. FASEB J 1994, 8: 1279-1284

14. Stampfer MJ, Hennekens CH, Manson JE, Colditz GA, Rosner B. Wilett WC: Vitamin E consumption and the risk of coronary disease in women. N Engl J Med 1993, 328: 1444-1449

15. Rimm EB. Stampfer MJ, Ascherio A, Giovannucci E, Colditz GA, Willett WC: Vitamin E consumption and the risk of coronary heart disease in men. N Engl J Med 1993, 328: 1450-1456

16. Buckley MM, Goa KL, Price AH, Brogden RN: Probucol. A reappraisal of its pharmacological properties and therapeutic use in hypercholesterolacmia. Drugs 1989, 37: 761-800

17. Carew TE. Schwenke DC, Stcinberg D: Antiatherogenic effect of probucol unrelated to its hypocholesterolemic effect: evidence that antioxidants in vivo can selectively inhibit low density lipoprotein degradation in macrophage-rich fatty streaks and slow the progression of atherosclerosis in the Watanabe heritable hyperlipidemic rabbit. Proc Natl Acad Sci USA 1987, 84: 7725-7729

18. Kita T, Nagano Y, Yokode M, Ishii K, Kume N, Ooshima A, Yoshida H, Kawai C: Probucol prevents the progression of atherosclerosis in Watanabe heritable hyperlipidemic rabbit, an animal model for familial hypercholesterolemia. Proc Natl Acad Sci USA 1987, 84: 5928-5931

19. O'Brien K, Nagano Y, Gown A, Kita T, Chait A: Probucol treatment affects the cellular composition but not anti-oxidized low density lipoprotein immunoreactivity of plaques from Watanabe heritable hyperlipidemic rabbits. Arterioscler Thromb 1991, 11: 751-759

20. Sasahara M, Raines EW, Chait A, Carew TE, Steinberg D, Wahl PW, Ross R: Inhibition of hypercholesterolemia-induced atherosclerosis in the nonhuman primate by probucol. I. Is the extent of atherosclerosis related to resistance of LDL to oxidation? J Clin Invest 1994, 94: 155-164

21. Wissler RW: New insights into the pathogenesis of atherosclerosis as revealed by PDAY. Atherosclerosis 1994, 108(Suppl): S3-S20

22. Ferns GA, Forster L, Stewart-Lee A, Nourooz-Zadeh J, Änggård EE: Probucol inhibits mononuclear cell adhesion to vascular endothelium in the cholesterol-fcd rabbit. Atherosclerosis 1993, 100: $171-181$

23. Walldius G, Erikson U, Olsson AG, Bergstrand L, Hådell K, Johansson J, Kaijser L, Lassvik C, Mölgaard J, Nilsson S, SchäferElinder L, Stenpor G, Holmc I: The effect of probucol on femoral atherosclerosis: the probucol Quantitative Regression Swedish Trial (PQRST). Am J Cardiol 1994, 74: 875-883

24. Demer LL, Watson KE, Boström K: Mechanism of calcification in atherosclerosis. Trends Cardio Med 1994, 4: 45-49

25. Shanahan CM, Cary NR, Metcalfe JC, Weissberg PL: High expression of genes for calcification-regulating proteins in human atherosclerotic plaques. J Clin Invest 1994, 93: 2393-2402

26. Ooyama T: Extracellular matrix in vessel wall. Byotaiseiri (Pathological Physiology) 1991, 10: 32-39 (in Japanese) 